\title{
SURGIMIENTO Y CONSOLIDACIÓN DE LA RESPONSABILIDAD INTERNACIONAL INDIVIDUAL POR CRÍMENES DE GUERRA COMETIDOS EN CONFLICTOS ARMADOS NO INTERNACIONALES*
}

\author{
Juan Pablo Pérez-León Acevedo**
}

\begin{abstract}
RESUMEN
La presente investigación busca estudiar el proceso de surgimiento y afianzamiento de la figura de la responsabilidad internacional individual por crímenes de guerra cometidos en el contexto de conflictos armados no internacionales, los cuales han caracterizado el Derecho internacional contemporáneo. Para tal efecto, se hace un estudio de la respectiva norma de Derecho internacional consuetudinario la cual se cristalizó en el Derecho internacional convencional, representado por el Estatuto de la Corte Penal Internacional.
\end{abstract}

\section{PALABRAS CLAVES}

Crímenes de guerra, conflicto armado no internacional, Estatuto de la Corte Penal Internacional, Derecho internacional humanitario, responsabilidad internacional individual.

\footnotetext{
* Artículo recibido el 14 de agosto de 2007 y aprobada su publicación el 10 de septiembre.

** Bachiller en Derecho, abogado. Asesor legal, Amnistía Internacional, Sección Peruana, Temas de Derechos Humanos, Derecho Penal Internacional, Derecho Internacional Humanitario y Derecho Internacional, agosto 2006 hasta la fecha. Adjunto de docencia del curso de Derecho Internacional Público en la Facultad de Derecho de la Pontificia Universidad Católica del Perú. E-mail: jperezleon@gmail.com.
} 


\begin{abstract}
The present research seeks to study the process of emergence and consolidation of the institution of international individual responsibility for war crimes committed in the context of non-international armed conflicts, which have characterized contemporary International law. In order to reach that purpose, it is studied the respective customary international humanitarian law rule which crystallized in the treaty international law, represented by the International Criminal Court Statute.
\end{abstract}

\title{
KEY WORDS
}

War crimes, non-international armed conflict, International Criminal Court Statute, International humanitarian law, international individual responsibility.

\section{Introducción}

Los crímenes de guerra, en términos generales, son las violaciones serias del Derecho internacional humanitario (DIH) -el cual regula la conducción de hostilidades durante un conflicto armado- que generan responsabilidad internacional individual siendo que los perpetradores pueden ser juzgados ya sea por tribunales nacionales o internacionales. Los crímenes de guerra constituyen la más antigua de las categorías de crímenes de Derecho internacional (DI). Como rasgo esencial de los crímenes de guerra, tenemos que una conducta (acción u omisión) necesita haber sido cometida no sólo durante un conflicto armado sino también en conexión con él ${ }^{1}$.

Sobre los elementos de un conflicto armado, el Tribunal Penal Internacional para la ex Yugsolavia (TPEY) en el caso Tadic señaló que " [...] an armed conflict exists whenever there is a resort to armed force between States or protracted armed violence between governmental authorities and organized armed groups or between such groups within a State"2 . De lo anterior se desprende que un conflicto armado tiene cuatro elementos fundamentales: uno definitorio esencial, que es el de la fuerza o violencia armada; uno temporal que es la prolongación en el tiempo; el factor organizativo del grupo participante en el conflicto armado y; la inclusión del conflicto armado entre grupos en adición a las clásicas concepciones de conflicto armado internacional (CAI) o de conflicto armado no internacional (CANI).

Prosecutor vs. Tadic, caso n. ${ }^{\circ}$ IT-94-1-T, sentencia de 7 de mayo de 1997, parágrafo 572.

Prosecutor vs. Tadic, caso n. ${ }^{\circ}$ IT-94-1-T, sentencia de 7 de mayo de 1997, parágrafo 628. Asimismo, el TPR en el caso Akayesu sostuvo que "[...] The term, 'armed conflict' in itself suggests the existence of hostilities between armed forces organized to a greater or lesser extent". Prosecutor vs. Akayesu, caso n. ${ }^{\circ}$ ICTR-96-4-T, sentencia de 2 de septiembre de 1998, parágrafo 620. También véase Prosecutor vs. Musema, caso n. ${ }^{\circ}$ ICTR- $^{-}$ 96-13-A, sentencia de 27 de enero de 2000, parágrafo 248. 
Surgimiento y consolidación de la responsabilidad internacional individual por crímenes de guerra cometidos en conflictos armados no internacionales

Los crímenes de guerra fueron los primeros en ser perseguidos por el DI. Así tenemos que, en los Juicios de Leipzig, como consecuencia del Tratado de Versalles ${ }^{3}$, se encontraron culpables a soldados alemanes por la violación de "las leyes y costumbres de la guerra". La base en DI para la criminalización de tales ofensas fue la Regulación anexa a la Convención IV de la Haya de $1907^{4}$, aunque debe precisarse que este instrumento no contiene disposiciones precisas sobre la determinación de la responsabilidad internacional individual. Los crímenes de guerra también fueron tipificados en los Estatutos de los Tribunales de Nüremberg y Tokio ${ }^{5}$. Posteriormente, el sistema de las infracciones graves (categoría de crímenes de guerra aplicables a un conflicto armado internacional) de los cuatro Convenios de Ginebra de 1949 y de su Protocolo Adicional I continuó con este desarrollo ${ }^{6}$.

La evolución de la tipificación de los crímenes de guerra ha seguido con el Estatuto del $\mathrm{TPEY}^{7}$; el estatuto del Tribunal Penal Internacional para Ruanda (TPR), el cual fue el primer instrumento internacional que tipifica los crímenes de guerra en un $\mathrm{CANI}^{8}$; el Estatuto de la Corte Penal Internacional (CPI), primer tratado multilateral que tipifica los crímenes de guerra en un $\mathrm{CANI}^{9}$; Corte Especial para Sierra Leona $^{10}$; la regulación especial para Timor Oriental ${ }^{11}$; la Law on the Khmer Rouge Trial de Camboya ${ }^{12}$ y el Proyecto de Código de Crímenes contra la Paz y Seguridad de la Humanidad de la Comisión de Derecho Internacional (CDI $)^{13}$ prosiguieron la misma dirección.

Precisamente, el presente trabajo de investigación busca analizar el desarrollo de los crímenes de guerra cometidos en un CANI. Debido a la proliferación de este tipo de conflictos armados en las últimas décadas, creemos que el análisis del tema seleccionado, dentro del marco del DI contemporáneo, adquiere especial importancia. Antes de pasar al estudio de nuestra institución, debemos recordar que dentro de la categoría del CANI se distinguen dos

Tratado de Versalles, artículos 228-230.

Nos referimos al Reglamento relativo a las leyes y costumbres de la guerra terrestre de 18 de octubre de 1907; reglamento anexo a la Convención relativa a las leyes y costumbres de la guerra terrestre de la misma fecha.

Estatuto del Tribunal Militar Internacional de Nüremberg, artículo 6.b; Estatuto del Tribunal Militar Internacional de Tokio, artículo 5.b.

6 Cuatro Convenios de Ginebra de 12 de agosto de 1949; Protocolo Adicional I a los Convenios de Ginebra del 12 de agosto de 1949 relativo a la protección de las víctimas de los conflictos armados internacionales de 8 de junio de 1977.

$7 \quad$ Estatuto del TPEY, artículo 2. Infracciones graves a los Convenios de Ginebra de 1949; artículo 3. Violaciones de las leyes o prácticas de guerra.

Estatuto del TPR, artículo 4. Violaciones del artículo 3 común a las Convenciones de Ginebra y al PA II.

Estatuto de la CPI, artículo 8. Crímenes de guerra.

Estatuto de la Corte Especial para Sierra Leona, artículo 3 (Violaciones del Artículo 3 común a los Convenios de Ginebra y del PA II) y artículo 4 (Otras violaciones serias del DIH).

UNTAET Regulation No. 2000/15 para Timor Oriental, sección VI (crímenes de guerra).

Law on the Khmer Rouge Trial de Camboya de 2001, artículos 6 y 7.

Proyecto de Código de crímenes contra la Paz y Seguridad de la Humanidad de 1996, artículo 20. 
tipos de conflictos armados. Así tenemos aquéllos regidos por el artículo 3 común a los 4 Convenios de Ginebra y a los que les es aplicable además el Protocolo Adicional II a los Convenios de Ginebra (PA II $)^{14}$, si es que se cumplen los requisitos que éste exige. Respecto a los CANI regidos por el artículo 3 común se requieren dos condiciones. La primera es que el conflicto armado no sea de carácter internacional. Ello, implica que se trate de una acción armada, es decir, que se de la presencia de hostilidades lo cual conlleva la existencia de un carácter colectivo y una mínima organización. La segunda consiste en que se desarrolle en el territorio de una de las altas Partes Contratantes, aunque no se exige un control territorial duradero ni tampoco un número determinado de operaciones militares o víctimas.

A su vez, para la aplicación del PA II a un CANI los requisitos que éste exige son: a) necesariamente debe involucrar entre los actores del conflicto a fuerzas armadas estatales que se enfrenten ya sea contra fuerzas armadas disidentes o contra grupos armados organizados; $b$ ) el grupo adverso debe contar con un mando responsable, lo que alude a un grado importante de organización y disciplina de las tropas respectivas; c) el grupo adverso debe poseer control territorial, que permita el desarrollo de operaciones militares sostenidas y concertadas; d) el grupo adverso debe estar en la capacidad de efectuar operaciones militares sostenidas y concertadas, lo que excluye actos aislados de violencia y; e) tener capacidad de aplicar el PA $\mathrm{II}^{15}$.

Finalmente, debido a las múltiples referencias que se van a hacer a los conflictos armados de Ruanda, Sierra Leona y en la ex Yugoslavia; se debe precisar que mientras los dos primeros pertenecen a la categoría de CANI regulados tanto por el artículo 3 común como por el PA II, el tercero pertenece a la categoría de los denominados CANI internacionalizados ${ }^{16}$.

\section{Labor del Consejo de Seguridad de Naciones Unidas}

El Consejo de Seguridad de Naciones Unidas tomó la iniciativa de señalar el principio por el cual toda violación grave de DIH aplicable a los CANI genera la responsabilidad internacional individual de su autor. Tal iniciativa fue seguida por algunos Estados que adaptaron su legislación (códigos penales, códigos de justicia militar y manuales militares) a tal fin, lo cual también se reflejó en la jurisprudencia de sus tribunales. El compromiso del Consejo de Seguridad en

\footnotetext{
14 Protocolo Adicional II a los Convenios de Ginebra del 12 de agosto de 1949 relativo a la protección de las víctimas de los conflictos armados no internacionales de 8 de junio de 1977.

15 Véase PA II, artículo 1. Tenemos como ejemplo los CANI desarrollados en Filipinas, la ex Yugoslavia, Georgia, El Salvador, Eritrea, Colombia.

16 Un CANI internacionalizado es aquel conflicto en el cual "uno o varios Estados extranjeros intervienen con sus propias fuerzas armadas a favor de una de las Partes". Verri, Pietro, Diccionario de Derecho Internacional de los conflictos armados. Tercer Mundo Editores, Bogotá 1998, p. 26.
} 
Surgimiento y consolidación de la responsabilidad internacional individual por crímenes de guerra cometidos en conflictos armados no internacionales

relación a la sanción de las violaciones serias del DIH perpetradas en el contexto de un CANI tiene como punto de partida el inicio de la última década del siglo pasado, siendo referentes paradigmáticos los casos de la ex Yugoslavia y de Ruanda.

En el contexto de la ex Yugoslavia y sin pronunciarse sobre la naturaleza de los conflictos armados que se desarrollaban en su territorio, el Consejo de Seguridad pidió a través de la Resolución 771 a los Estados y organismos humanitarios la recolección de información sobre las violaciones del DIH y a comunicarle las mismas ${ }^{17}$. De igual manera en la Resolución citada se enunció el principio por el cual toda violación grave del DIH genera responsabilidad internacional individual de su autor, al señalar que "todas las partes en el conflicto deben cumplir las obligaciones que les incumben con arreglo al derecho internacional humanitario internacional y, en particular, con los Convenios de Ginebra de 12 de agosto de 1949, y que quienes cometan u ordenen que se cometan transgresiones graves de los Convenios son personalmente responsables de ellas"18.

Por medio de la Resolución 787, el Consejo de Seguridad ratificó lo anterior, aunque en esta ocasión se refirió de manera más amplia a todas las violaciones del DIH, sin hacer alusión expresa a los Cuatro Convenios de Ginebra, al condenar "todas las violaciones del derecho humanitario internacional, incluyendo en particular la práctica de la "depuración étnica" y la obstaculización deliberada de la entrega de alimentos y suministros médicos a la población civil de la República de Bosnia y Herzegovina, y reafirma que se considerarán responsables individualmente de esos actos a aquellos que los cometan o que ordenen su comisión"19.

A raíz del CANI que se produjo en Somalia, el Consejo de Seguridad aprobó de manera unánime dos resoluciones, en las cuales declaró que los autores o personas que hayan ordenado cometer violaciones graves del DIH incurrieron en responsabilidad internacional individual. El Consejo exigió que "todas las partes somalíes, incluidos los movimientos y facciones, pongan término inmediatamente a todas las violaciones del derecho humanitario internacional, y reafirma que los autores de esos actos serán considerados personalmente responsables" ${ }^{20}$. Similar contenido se puede encontrar en algunas resoluciones aprobadas respecto a los CANI de Burundi $^{21}$, Liberia ${ }^{22}$ y Ruanda. En el marco de este último conflicto, se señaló de manera expresa la responsabilidad internacional individual de los perpetradores en un contexto de CANI, en tanto el Consejo de Seguridad, entre otros aspectos, condenó "todas las violaciones

17 S/RES/771 (1992), parágrafo 3. Resolución de 13 de agosto de 1992.

18 S/RES/771 (1992), parágrafo 1. Resolución de 13 de agosto de 1992.

19 S/RES/787 (1992), parágrafo 7. Resolución de 16 de noviembre de 1992.

20 S/RES/814 (1993), parágrafo 13. Resolución de 26 de marzo de 1993. Véase también S/RES/794 (1992), parágrafo 5 .

21 Véanse S/RES/1012. Resolución de 28 de agosto de 1995 y S/RES/1072. Resolución de 30 de agosto de 1996.

22 S/RES/788 (1992). Resolución de 19 de noviembre de 1992, parágrafo 5: 
del derecho internacional humanitario en Rwanda, en particular aquéllas de que había sido víctima la población civil, y recordó que las personas que participaban en esos actos o los instigaban eran responsables de ellos a título individual ${ }^{23}$ ".

Se puede afirmar que el paso determinante en la penalización de las violaciones del DIH aplicable a los CANI fue la creación de los dos Tribunales Penales Internacionales ad hoc. Para tal decisión el Consejo de Seguridad se basó en el capítulo VII de la Carta de Naciones Unidas, y de esa forma creó como órganos subsidiarios jurisdiccionales del Consejo tanto al TPEY como al TPR. Resulta de especial valía resaltar que la finalidad fundamental de la constitución del TPR, fue sancionar (junto al genocidio) las graves transgresiones del DIH acontecidas en el CANI que sucedieron en ese Estado en 1994. En efecto, la finalidad fue "establecer un tribunal internacional con el propósito exclusivo de enjuiciar a los responsables de $[\ldots]$ otras graves violaciones del derecho internacional humanitario cometidas en el territorio de Rwanda y a ciudadanos de Rwanda responsables de genocidio y otras violaciones de esa naturaleza cometidas en el territorio de Estados vecinos entre el $1^{\circ}$ de enero de 1994 y el 31 de diciembre de $1994[\ldots]^{\prime 24}$.

Por otro lado, el Consejo de Seguridad entendió que el principio de jurisdicción universal era factible de aplicarse a las violaciones graves del DIH en el desarrollo de un CANI « sans s'appuyer sur la notion d'infraction grave ou de crime de guerre, élément pivot du système de répression prévu par les instruments de Genève ${ }^{25}$. En la Resolución 978, el Consejo de Seguridad también exhortó a los Estados (mientras se concretizaba la constitución del TPR) a que ejerzan jurisdicción universal en relación a los sujetos responsables de la comisión de crímenes de DI (entre ellos las violaciones graves del DIH en el CANI ruandés) ${ }^{26}$.

Por su parte, el TPEY en el caso Tadic ha resaltado la importancia de las resoluciones del Consejo de Seguridad en la afirmación de la generación de responsabilidad internacional individual en un contexto de CANI, con miras a la formación de una opinio juris al haber sido adoptadas unánimemente por el Consejo. En palabras del TPEY tenemos que "of great relevance to the formation of opinio juris to the effect that violations of general international humanitarian law governing armed conflicts entail the criminal responsibility of those committing or ordering those violations are certain resolutions unanimously adopted by the Security Council ${ }^{27}$ ". En el

S/RES/935 (1994), preámbulo. Resolución de 1 de julio de 1994.

S/RES/955 (1994), parágrafo 1. Resolución de 8 de noviembre de 1994

Boisson de Chazourness, $\mathrm{L}$ « Les résolutions des organes des Nations Unies, en particulier celles du Conseil de sécurité, en tant que sources du droit international humanitaire », en Condorelli, Luigi y A.M, La Rosa (ed.), Pedone, París, 1996, p. 157. Citado por Momtaz, Djamchid, « Le droit international humanitaire applicable aux conflits armés non internationaux » en Recueil des Cours de la Académie de Droit International, volumen 292, 2001, p. 108.

26 S/RES/978 (1995), parágrafo 1. Resolución de 27 de febrero de 1995.

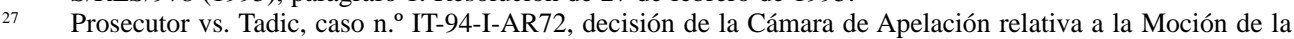


Surgimiento y consolidación de la responsabilidad internacional individual por crímenes de guerra cometidos en conflictos armados no internacionales

mismo parágrafo se citó de manera expresa el ejemplo de las dos resoluciones adoptadas sobre el CANI acontecido en Somalia, antes referidas ${ }^{28}$.

El Consejo de Seguridad, ha seguido la línea de expresar la responsabilidad internacional del individuo por la comisión de violaciones graves del DIH en un contexto de CANI. Constituye un buen y más reciente ejemplo de lo anterior la constitución de la Corte Especial para Sierra Leona que tiene competencia para juzgar a individuos acusados de cometer violaciones del DIH en un CANI, afirmándose nuevamente el principio de responsabilidad internacional individual. En este sentido, en la Resolución 1315 relativa a la situación en Sierra Leona, se establece que "las personas que cometen o autorizan violaciones graves del derecho internacional humanitario son responsables de tales violaciones a título personal y deben rendir cuentas al respecto, y que la comunidad internacional hará todo lo necesario por llevar a los responsables ante la justicia de conformidad con las normas internacionales de la justicia, la imparcialidad y el respeto de las garantías legales" 29 . En adición a ello la resolución anterior, a diferencia de las resoluciones sobre la ex Yugoslavia y Ruanda, utiliza el término crímenes de guerra además de violaciones graves del DIH, en consonancia con la terminología adoptada por el Estatuto de la $\mathrm{CPI}^{30}$.

\section{Trabajos de la Comisión de Derecho Internacional}

Analizaremos en esta sección dos proyectos elaborados por la CDI. El primero es el Proyecto de Estatuto de CPI de $1994^{31}$, el cual en relación a los crímenes de guerra distinguió entre crímenes de DIH consuetudinario y crímenes definidos en tratados ${ }^{32}$. De conformidad con los criterios generales de selección de instrumentos internacionales, la CDI señaló que había excluido aquellos tratados que únicamente regulaban o prohibían una conducta a nivel interno sin contener normas relativas a la responsabilidad internacional individual ni un sistema de jurisdicción universal ${ }^{33}$. Sobre tal fundamento, se excluyó, entre otros, al PA II. En opinión de la CDI este instrumento prohíbe conductas pero no contempla cláusulas relativas a infracciones graves ${ }^{34}$.

Como se deduce de lo anterior, la CDI consideró que se debían cumplir dos requisitos para que una conducta califique como crimen de guerra. Por un lado, se debía hacer efectiva la

\footnotetext{
Defensa sobre la Jurisdicción de 2 de octubre de 1995, parágrafo 133. Defensa sobre la Jurisdicción de 2 de octubre de 1995, parágrafo 133. S/RES/1315 (2000). Resolución de 14 de agosto de 2000, preámbulo. S/RES/1315 (2000). Resolución de 14 de agosto de 2000, parágrafo 3 concordado con el parágrafo 2. CDI. Informe en su $46^{\circ}$ periodo de sesiones, 2 de mayo a 22 de julio de 1994. UN Doc. A/49/10, p. 52. Véase el artículo 20 del Proyecto. CDI. Informe en su $46^{\circ}$ periodo de sesiones, 2 de mayo a 22 de julio de 1994. UN Doc. A/49/10, pp. 84. Ibid., p. 109.
} 
responsabilidad internacional de los perpetradores. Por otro lado, se debía prever la obligación para cada Estado de ejercer jurisdicción universal a través del mecanismo de aut dedere aut judicare. En este marco, el Proyecto sólo incluyó violaciones del DIH acontecidas en el marco de un CAI, lo cual reflejó la por entonces interpretación mayoritaria ${ }^{35}$ en virtud de la cual ni las violaciones al artículo 3 común ni al PA II se integraban al sistema penal internacional, toda vez que no cumplían con los dos requisitos señalados ${ }^{36}$. Sin embargo, la propia CDI había señalado que la expresión crímenes de guerra tenía en cuenta a todos los tipos de conflicto $\operatorname{armado}^{37}$.

El segundo documento a considerar es el Proyecto de Código de Crímenes contra la Paz y Seguridad de la Humanidad de 1996. Luego de algunos debates ${ }^{38}$, la CDI incorporó como crímenes de guerra los actos que violan el DIH aplicable en un $\mathrm{CANI}^{39}$. De esa forma, se reconoció que en el DI actual, el cual debe aplicarse en un contexto de proliferación de CANI, es acertado hablar de la generación de responsabilidad internacional individual por crímenes de guerra cometidos en un $\mathrm{CANI}^{40}$. Asimismo, de manera innovadora se consideró que un daño extenso, duradero y severo al medio ambiente tanto en un CAI como en un CANI constituye un crimen de guerra ${ }^{41}$, aunque en el Estatuto de la CPI no se ha considerado como crimen de guerra en un CANI.

\section{Proceso de negociación del Estatuto de la Corte Penal Internacional}

En general, la mayor dificultad fue seleccionar qué conductas debían considerarse como crímenes de guerra, por lo cual se estimó que debían cumplir tres requisitos: carácter consuetudinario; contener bases para la imputación de responsabilidad internacional individual y tener la suficiente gravedad. En tal sentido, en principio sólo las infracciones graves a los Convenios de Ginebra, las cuales son aplicables únicamente en un CAI, calificaban como crímenes de guerra.

En este contexto, se dio la presentación en el Comité Preparatorio de dos propuestas: la

Véase, por ejemplo, Plattner, Dense, "The penal Repression of Violations of International Humanitarian Law Applicable in Non-international Armed Conflicts" en Revista Internacional de la Cruz Roja, vol. 30, 1990, pp. 409-414.

36 Fernández de Gurmendi, Silvia, "El Estatuto de Roma de la Corte Penal Internacional: Extensión de los crímenes de guerra a los conflictos armados de carácter no internacional y otros desarrollos relativos al Derecho internacional humanitario" en AAVV, Derecho internacional humanitario y temas de área vinculadas, CICR / Facultad de Derecho de la UBA / Abeledo-Perrot, Buenos Aires, 2003, p. 393.

37 CDI. Reporte de su 41 a sesión de trabajo, 2 de mayo-21 de julio de 1989, UN Doc. A/44/10, p. 59.

38 UN Doc. A/CN.4/L.532, 8 de julio de 1996.

39 Proyecto de Código de Crímenes contra la Paz y Seguridad de la Humanidad, artículo 20. War crimes.

40 CDI. Reporte de su $48^{a}$ sesión de trabajo, 6 de mayo-26 de julio de 1996, UN. Doc. A/51/10, p. 141.

41 Proyecto de Código de Crímenes contra la Paz y Seguridad de la Humanidad de 1996, artículo 20. War crimes. 
Surgimiento y consolidación de la responsabilidad internacional individual por crímenes de guerra cometidos en conflictos armados no internacionales

primera de Estados Unidos ${ }^{42}$ y la segunda de Suiza y Nueva Zelanda ${ }^{43}$, basada en un documento de trabajo elaborado por el Comité Internacional de la Cruz Roja ${ }^{44}$. Ambas incluyeron dentro de la categoría de los crímenes de guerra, además de las infracciones graves de los Convenios de Ginebra, las violaciones al artículo 3 común $^{45}$. Sin embargo, difirieron en la base jurídica utilizada para definir los crímenes de guerra que acarrean responsabilidad internacional individual así como en el número de crímenes de guerra seleccionados ${ }^{46}$. En tal sentido, la propuesta americana dio contenido a la categoría de "otras violaciones graves" con normas provenientes del Reglamento de la Haya (para el supuesto de CAI). Frente a esta posición, la otra propuesta, bastante más extensa, también incorporó entre otras normas a las infracciones graves del Protocolo Adicional I a los Convenios de Ginebra (para CAI) así como algunas disposiciones del PA II (contexto de CANI).

En 1997, ${ }^{47}$ se logró conciliar ambas posiciones con la preparación de un documento que, en el caso de los CANI, incluyó violaciones al artículo 3 común a los Convenios de Ginebra así como otras disposiciones consideradas como esenciales en la conducción de este tipo de conflictos armados, aunque no se logró alcanzar el consenso deseado. Es así que, la actual redacción del artículo 8 se va a lograr hacia el final de la Conferencia de Roma, en la que finalmente se incorporaron como crímenes de guerra de competencia de la CPI, conductas efectuadas en el marco de un CANI. Durante las negociaciones existió resistencia a esta incorporación, en tanto, se sostuvo la ausencia de fundamento para la determinación de la responsabilidad internacional individual en relación a violaciones del artículo 3 común así como la carencia de carácter consuetudinario del PA II. A ello se sumaron razones de supuesto realismo político ${ }^{48}$. No obstante, se logró la incorporación señalada lo cual es una garantía para la efectividad de la CPI, en tanto, la gran mayoría de conflictos actuales son CANI.

\section{Práctica estatal}

Primeramente, centraremos nuestro análisis en el contexto producido a raíz de la expedición de la Resolución 827 del Consejo de Seguridad ${ }^{49}$, por la cual se aprobó el informe del Secretario

Propuesta de los Estados Unidos, Doc. UN A/AC.249/1997/WG.1/DP.1 de 14 de febrero de 1997. Propuesta de Nueva Zelanda y Suiza, Doc. UN A/AC.249/WG.1/DP.2 de 14 de febrero de 1997.

Véase Comité Internacional de la Cruz Roja. Crimes de guerre. Documento de trabajo preparado para el Comité preparatorio para la creación de una Corte Penal Internacional. Nueva York, 14 de febrero de 1997.

45 Proyecto de texto de síntesis, Doc. UN/A/AC.249/19977WG.1/CRP.2.

46 Roberge, Marie-Claude, "Los crímenes de guerra en el Estatuto de Roma" en Guevara José y Mariana, Valdés (eds.), La Corte Penal Internacional. Ensayos para la Ratificación e Implementación de su Estatuto. Universidad Iberoamericana /Secretaría de Relaciones Exteriores, México D.F, 2002, pp. 74-75.

47 Véase Texto de Bonn, en: A/AC.249/19997/WG.1/CRP.8, de 15 de diciembre de 1997.

48 Informe del Comité Preparatorio sobre el establecimiento de una CPI, vol. I. Asamblea General. Documentos oficiales, $55^{\circ}$ periodo de sesiones, Suplemento 22 (A/51/22), p. 21.

49 S/RES/827 (1993). Resolución de 25 de mayo de 1993. 
General respecto a la creación del TPEY. En relación a los pronunciamientos relativos a la atribución de responsabilidad internacional individual tenemos lo señalado por la representante de los Estados Unidos. La señora Albright señaló que la expresión leyes o costumbres de la guerra (artículo 3 del Estatuto del TPEY) abarca también el artículo 3 común y el PA II “[...] « laws or customs of war » in Article 3 of the Statute include all obligations under humanitarian law agreements in force in the territory of the former Yugoslavia at the time the acts were committed, including common article 3 of the 1949 Geneva Conventions, and the 1977 Additional Protocols to these Conventions" ${ }^{50}$.

En igual sentido, se pronunció el delegado francés al sostener que "["leyes o costumbres de la guerra"] recouvre notamment, de l'avis de la France, toutes les obligations qui découlent des accords en matière de droit humanitaire en vigueur sur le territoire de l'ex-Yougoslavie à la date où les actes incriminés ont été commis" ${ }^{51}$. También son rescatables los pronunciamientos de España y Hungría ${ }^{52}$. De lo anterior así como de la afirmación constante de aplicar el DIH, se puede derivar el entendimiento de ciertos Estados de aplicar jurisdicción universal en caso de violaciones graves del DIH, cometidas durante un CANI. Como veremos más adelante en la memoria del amicus curiae de Estados Unidos en el caso Tadic, se llegó a afirmar incluso la aplicación de las infracciones graves a un $\mathrm{CANI}^{53}$. Por su lado, declaraciones de Estados miembros de la Unión Europea oscilaron entre la referencia única y expresa al régimen de infracciones graves y su extensión a un $\mathrm{CANI}^{54}$.

Entre los manuales militares, podemos mencionar como ejemplo al manual militar alemán de 1992, el cual se refiere al artículo 3 común de los Convenios de Ginebra y al PA II, al hacer una lista no exhaustiva de infracciones graves contra el $\mathrm{DIH}^{55}$. Asimismo, en el suplemento comentado al Commander's Handbook on the Law of Naval Operations de Estados Unidos de 1989 se hace una remisión constante al PA II respecto a algunos ejemplos de "crímenes de guerra" ${ }^{56}$. El manual militar italiano de 1991 estableció que las infracciones (actos ilícitos graves) contra los Convenios de Ginebra y sus Protocolos (incluyendo el PA II) son crímenes de guerra. Por otro lado, en diversos manuales militares se agruparon bajo la noción "crimen

50 UN Doc. S/PV.3217, 25 de mayo de 1995, p. 15.

51 UN Doc. S/PV.3217, 25 de mayo de 1995, p. 11 (declaración del señor Ladsous).

52 Respectivamente: UN Doc. S/PV.3217, 25 de mayo de 1995, p. 20 (declaración del señor Erdos); UN Doc. S/ PV.3217, 25 de mayo de 1995, p.39 (declaración del señor Yañez-Barnuevo).

53 Véase Prosecutor vs. Tadic, Submission of the Government of the United States of America Concerning Certain Arguments Made by Counsel for the Accused de 17 de Julio de 1995, pp. 35-36.

54 Declaración común de 6 de agosto de 1992. En: Boletín de las Comunidades Europeas, Comisión, n. ${ }^{\circ} 7 / 8$, 1992, pp. 114-115.

55 Citado por: Graditzky, Thomas, "La Responsabilidad penal por violación del derecho internacional humanitario aplicable en situación de conflicto armado no internacional” en Revista Internacional de la Cruz Roja, n. ${ }^{\circ} 145$, 1998, p. 39.

56 Citado por ibid., loc. cit. 
Surgimiento y consolidación de la responsabilidad internacional individual por crímenes de guerra cometidos en conflictos armados no internacionales

de guerra" todas las violaciones serias del derecho de los conflictos armados ${ }^{57}$. Aunque en algunos de estos manuales el uso de la nomenclatura no era técnicamente exacto, permitió calificar como crímenes de guerra a las violaciones graves del DIH cometidas durante un CANI.

En tal sentido, se observó el inicio de una tendencia especialmente desde comienzos de la década pasada, por la que se incriminan violaciones graves del DIH aplicable en el contexto de un CANI, utilizando en ciertos casos el término crímenes de guerra ${ }^{58}$. No obstante, en otros supuestos también se cometió la inexactitud jurídica de calificarse tales violaciones como infracciones graves, régimen aplicable sólo a un CAI.

Entre las legislaciones penales nacionales, tenemos que Bélgica fue el primer Estado que, a través de una ley en $1993^{59}$ (modificada en 1999) erigió como crímenes de guerra ciertas violaciones graves del DIH cometidas en el contexto de un CANI. El campo de aplicación material de esta ley (en relación a un CANI) se limita a los conflictos regulados por el PA II y confiere a los tribunales belgas jurisdicción para juzgar veinte infracciones pertenecientes a esa categoría de $\mathrm{CANI}^{60}$. En esta misma ley se señala que la competencia de las jurisdicciones belgas no tiene limitación territorial y no se exige tampoco vínculo de nacionalidad ${ }^{61}$. Como comentarios relacionados al contenido de esta ley podemos señalar que en primer lugar, no abarca a los CANI de menor intensidad que no alcanzan el umbral del PA II y a los que les es aplicable el artículo 3 común. Asimismo, y como señaló Graditzki en su momento "con esta ley en la mano se podrían incriminar determinadas conductas mantenidas durante conflictos no internacionales, pese a no estar prohibidas en norma alguna del derecho internacional humanitario" ${ }^{62}$. Entonces, de manera relativamente temprana, la aprobación de esta ley generó la aceptación de responsabilidad internacional individual por graves violaciones del DIH, cometidas en el marco de un CANI.

Como segundo ejemplo tenemos el caso español a través de su código penal de $1995^{63}$, el cual incluyó entre las personas protegidas a aquéllas que lo están en virtud del PA II, y no restringió la competencia ratione personae y ratione loci. Por su parte, la Ley Orgánica del Poder Judicial señala que los tribunales españoles tienen jurisdicción para perseguir a quienquiera

Citado por ibid., loc. cit.

Citado por ibid., p, 38.

Loi du 16 juin 1993 relative à la répression des infractions aux conventions internationales de Genève du 12 août 1949 et aux Protocoles I et II du 8 juin 1997, additionnels à ses conventions. Véase ibid., p. 41.

Véase ibid., loc. cit.

Ibid., p. 42.

Ibid., p. 41.

Citado por Pueyo, Jorge, "Hacia un fortalecimiento de los mecanismos de represión de crímenes de guerra. Responsabilidad Internacional del Individuo. Tribunales Internos y Corte Penal Internacional” en Pueyo, Jorge y Julio, Urbina (eds.), El Derecho Internacional Humanitario en una Sociedad Internacional en Transición. Cruz Roja Española / Tórculo Edicións, Santiago de Compostela, 2002, p. 150. 
que haya cometido crímenes en cualquiera lugar, según la ley española y en virtud de los tratados y convenios internacionales ${ }^{64}$. De esa forma se abarcaría (en tanto no se hace una exclusión) al PA II, siendo que además sus artículos se encuentran recogidos en el título denominado crímenes contra la comunidad internacional.

En el continente europeo también tenemos los códigos penales dados en la década de los noventa, como los códigos finlandés, sueco, holandés, suizo, alemán, ruso, portugués, noruego así como de la ex Yugoslavia aprobado igualmente por Bosnia-Herzegovina, el código penal de Eslovenia y, en el contexto africano, podemos citar el código penal de Etiopía ${ }^{65}$.

Finalmente en el ámbito americano encontramos el código penal nicaragüense de $1997^{66}$ y la War Crimes Act americana de 1996. Por una enmienda a esta última ${ }^{67}$, se extendió la competencia de los tribunales nacionales, en particular a las violaciones del artículo 3 común de los Convenios de Ginebra, encuadrándolas en el concepto de crímenes de guerra. Se puede objetar que, de la redacción del texto se deriva que tal calificación se basa de manera exclusiva en el Derecho interno de los Estados Unidos y que, por lo tanto, no considera necesariamente aplicable a un CANI la noción de crimen de guerra tal y como es entendida en el DI. Sin embargo y como acertadamente comenta Graditzki "[...] parece por lo menos sintomático que se sitúen las violaciones del artículo 3 común en el mismo rango que las infracciones graves contra los Convenios de Ginebra" ${ }^{68}$. Con todo, es resaltable la intención del gobierno americano de eliminar los obstáculos impuestos a la competencia de sus tribunales internos, al igual que respecto a las violaciones del artículo 3 común, en lo concerniente al requisito de un nexo de nacionalidad o de pertenencia a las fuerzas armadas norteamericanas (ya sea como sujeto responsable o agraviado).

Como aspecto final de este punto, es necesario hacer referencia a los efectos que ha producido el artículo 8 del Estatuto de la CPI en las legislaciones nacionales, al reconocer la generación de responsabilidad internacional individual por la comisión de un crimen de guerra durante un CANI. Se puede distinguir un primer grupo de Estados que recurren a una tipificación expresa, o de remisión general al DI convencional (aunque sin basarse exclusivamente en el Estatuto de la CPI). Entre éstos tenemos los casos de Canadá, Finlandia, Estonia, Holanda, Italia, Argentina, Ecuador, Australia, Alemania, y Perú ${ }^{69}$. Por otro lado tenemos un grupo de

\footnotetext{
64 Ley orgánica 6/1985 del Poder Judicial de 1 de julio de 1985, artículo 23.4. Véase ibid., p. 149.

65 Citados por Graditzky, Thomas, op. cit., pp. 43 y ss.

Ibid., p. 45.

War Crimes Act de 1996. Sección 2401. War crimes. Enmienda aprobada el 9 de noviembre de 1997 por el Senado y por la Cámara de Representantes el 12 de noviembre de 1997. Sección 583, en Sassòli, Marco y Antoine, Bouvier (eds.), How does law protect in war? CICR, Genève, 1999, pp. 588-589.

68 Graditzky, Thomas, op. cit., p. 45.

69 Véase Pueyo, Jorge, op. cit., pp. 178 y ss.
} 
Surgimiento y consolidación de la responsabilidad internacional individual por crímenes de guerra cometidos en conflictos armados no internacionales

Estados cuyas legislaciones tipifican los crímenes de guerra y la respectiva generación de responsabilidad en caso de CANI por medio de una remisión al Estatuto de la CPI, o por una mera transcripción exacta de las categorías y definiciones recogidas en este tratado. Dentro de este supuesto están Nueva Zelanda, África del Sur, Uruguay y la República Democrática del Congo $^{70}$.

En lo que corresponde a la jurisprudencia de tribunales nacionales, tenemos el caso Karadzic, en el cual la corte competente estadounidense evaluó la atribución de responsabilidad internacional individual por la violación del DIH. En la sección titulada crímenes de guerra, la corte compara los supuestos actos cometidos en conexión con el artículo 3 común y se ubica, como resulta lógico, en un CANI. Es de especial importancia para nuestro tema, la admisión de la responsabilidad internacional individual en un CANI, equiparando el artículo 3 común con los Convenios de Ginebra "[...] Common article 3, which is substantially identical in each one of the four Conventions, applies to "armed conflicts not of an international character" and bind "each Party to the conflict...to apply, as a minimum, the following provisions [...]" tiempo determinó que el ámbito de aplicación ratione personae no se limita exclusivamente a los agentes estatales sino que, abarca a grupos militares insurgentes ${ }^{72}$. Por otro lado, reconoce la aplicación de la jurisdicción universal respecto a los crímenes de guerra, sin importar la clase de conflicto armado. Podemos deducir que, la corte suscribió la idea por la cual los crímenes de guerra, junto al ejercicio de jurisdicción universal, incluyen ciertas violaciones del DIH cometidas en un CANI.

En el contexto de los tribunales suizos encontramos un asunto relativo a los crímenes de guerra perpetrados en la ex Yugoslavia ${ }^{73}$. El acta de acusación se refiere de manera explícita (aunque no exclusivamente) al artículo 3 común y al PA II. No obstante, este tribunal expidió una sentencia absolutoria, por falta de medios probatorios. A pesar de ello, el Tribunal Militar de apelación suizo, en el caso Niyonteze, condenó a un ciudadano ruandés por los crímenes cometidos en el CANI desarrollado en ese Estado, siendo confirmada tal resolución por el Tribunal Militar de casación suizo ${ }^{74}$. El Tribunal Militar Penal de Suiza procesó a acusados de haber cometido violaciones contra las leyes y costumbres de la guerra bajo los Convenios de Ginebra y los dos Protocolos Adicionales. Sin embargo por materias probatorias se liberaron a los acusados ${ }^{75}$.

70 Ibid., pp. 182 y ss.

71 Segundo Circuito de la Corte de Apelaciones de Estados Unidos. Caso Kadic S. vs. Karadzic Radovan, decisión de 13 de octubre de 1995, en Sassòli, Marco y Antoine, Bouvier (eds.), op. cit., p. 1249.

Ibid., pp. 1249-1250.

73 Corte de derecho público. Caso X contra la Oficina Federal de la Policía (recurso de derecho administrativo), sentencia de 28 de abril de 1997.

74 Tribunal Militar de Casación. Caso Fulgente Niyonteze, sentencia de 27 de abril de 2001.

75 Tribunal militar suizo, sentencia de julio de 1997. Citado por Lekha, Sandra, "Revolutions in Accountability: 
En relación al conflicto armado ruandés también se han procesado a individuos en Estados europeos tales como Francia y Bélgica, aunque con disímiles fallos. En Bélgica, por ejemplo, distintas instancias judiciales confirmaron la generación de responsabilidad internacional individual en un CANI, al aplicar la ley de 1993 antes citada, ejerciendo jurisdicción universal ${ }^{76}$. Por otro lado, el TPR solicitó a Bélgica la extradición de ruandeses acusados de crímenes de guerra y genocidio, sin embargo por falta de evidencia Bélgica rechazó tal pedido, aunque aludió el ejercicio de jurisdicción universal. A su vez, Bélgica inició procesos contra cuatro ruandeses por violación del PA II en relación al genocidio cometido en Ruanda ${ }^{77}$. En Francia, la ausencia de los acusados en su territorio frustró tempranas persecuciones ${ }^{78}$. No obstante, en el caso Munyeshyaka, la Corte de Casación sobre la base de una nueva legislación, procesó al acusado, entre otros cargos, por la violación de las leyes y costumbres de la guerra ${ }^{79}$.

Respecto al contexto del conflicto armado acaecido en la ex Yugoslavia, además de la práctica de las instancias judiciales suizas, podemos citar los casos de otros Estados europeos. Así tribunales holandeses equipararon la situación de "guerra civil" con una "guerra", es decir un CANI con un CAI, a la vez que ejercían jurisdicción universal ${ }^{80}$. En Holanda, la Corte Suprema recurrió al concepto de jurisdicción universal como se encuentra regulada en los Convenios de Ginebra ${ }^{81}$. Por otra parte, la Alta Corte Danesa aplicó el régimen de las infracciones graves de los Convenios de Ginebra (Convenios III y IV) sin pronunciarse sobre la naturaleza del conflicto ${ }^{82}$. Este dato puede sugerirnos que la calificación de la naturaleza del conflicto armado no le pareció relevante para la aplicación de tal régimen. Asimismo, podemos citar la práctica de los tribunales húngaros ${ }^{83}$. En Alemania, las cortes se basaron en su código penal que, a su vez remitía a los instrumentos internacionales pertinentes que establecen la posibilidad de ejercer jurisdicción universal. En tal sentido, se determinó que los Convenios de Ginebra contienen las normas correspondientes ${ }^{84}$. Debemos recordar que, el Estado alemán transfirió al entonces detenido Tadic a la jurisdicción del TPEY. Finalmente, en Francia, a pesar de la

New Approaches to Past Abuses" en American University International Law Review, vol. 19, n. ${ }^{\text {o } 2, ~} 2003$, p. 342.

76 Corte de apelación de Bruselas, cámara de acusación, fallo de 17 de mayo de 1995; Corte de casación, segunda cámara, fallo de 31 de mayo de 1995; Tribunal de primera instancia del distrito de Bruselas, cámara del Consejo, ordenanza de 22 de julio de 1996. Véase Graditzky, Thomas, op. cit., p. 51

77 Véase Lekha, Sandra, op. cit., pp. 344-345.

78 Ibid., p. 344.

79 Corte de Casación de Francia-Cámara Criminal. Asunto Munyeshyaka, sentencia de 6 de enero de 1998, p. 827.

$80 \quad$ Citados por Graditzky, Thomas, op. cit., p. 49.

$81 \quad$ Citado por Lekha, Sandra, op. cit., p. 339.

82 Alta Corte Danesa, división oriental, tercera cámara. Caso Procurador vs. R. Saric, decisión de 25 de noviembre de 1994. Citado por Graditzky, Thomas, op. cit., p. 50.

83 Corte constitucional de la República de Hungría, decisión n. o 53/1993 (X. 13) AB y decisión n. ${ }^{\text {o }} 36 / 1996$ (IX.4.) AB. Citado por ibid., p. 51.

$84 \quad$ Citado por Lekha, Sandra, op. cit., p. 341. 
Surgimiento y consolidación de la responsabilidad internacional individual por crímenes de guerra cometidos en conflictos armados no internacionales

imputación de crímenes de guerra cometidos en la ex Yugoslavia, una corte rechazó los cargos en tanto se requirió la presencia material de los acusados ${ }^{85}$.

Ahora bien, a pesar de la relativa novedad en la formación de la costumbre de ejercer jurisdicción universal sobre crímenes de guerra cometidos en un CANI así como la presencia de problemas en algunos casos consideramos que existe una norma consuetudinaria que permite el ejercicio de una jurisdicción universal facultativa para estos casos. Por lo tanto, coincidimos con el Comité Internacional de la Cruz Roja en reconocer la existencia de una regla de DIH consuetudinario que otorgaría el derecho a los Estados de ejercer jurisdicción universal sobre crímenes de guerra cometidos no sólo en un CAI sino también en un $\mathrm{CANI}^{86}$, a partir de la práctica estatal, especialmente a raíz de los sucesos en Ruanda ${ }^{87}$.

En tal sentido y respecto al ámbito de la jurisdicción universal, mientras el DIH convencional se limita a las infracciones graves, el DIH consuetudinario abarca las violaciones graves de las leyes y los usos de la guerra (entre ellas, algunas violaciones graves relativas a los medios y métodos de guerra) que constituyen una categoría de crímenes de guerra, sean cometidas en un CAI o en un CANI. Asimismo, también comprende a las violaciones al artículo 3 común a los Convenios de Ginebra y a algunas normas del PA II a los Convenios de Ginebra. ${ }^{88}$

\section{Existencia de norma consuetudinaria de responsabilidad internacional individual por crímenes de guerra en un conflicto armado no internacional}

Consideramos pertinente, en este punto, formularnos la pregunta sobre si se ha cristalizado una norma consuetudinaria por la que se atribuya responsabilidad internacional individual en el contexto de un CANI. Frente a esta posibilidad existen básicamente dos obstáculos. El primero, se relaciona con la brevedad del tiempo transcurrido desde el momento en que esta práctica se instauró. Un aspecto inicial favorable fue la opinión del Secretario General por la que se consideró que el artículo 3 del Estatuto del TPEY abarca todos los medios y métodos de hacer la guerra sin tener en cuenta la clase de conflicto $^{89}$. Tal iniciativa, fue desarrollada de manera notable por la jurisprudencia del TPEY. Referencia inevitable es el caso Tadic, toda vez que el TPEY entendió que su competencia abarca las violaciones serias del DIH cometidas en un

\footnotetext{
Corte de apelación de Paris, cuarta cámara de apelación. Appel d'une ordonnance d'incompétence partielle et de recevabilité de constitution de parties civiles, asunto de 24 de noviembre de 1994 en el asunto Javor y otros contra X; confirmada por la sala penal de la corte de casación en sentencia de 26 de marzo de 1996. Henckaerts, Jean-Marie y Louise, Doswald-Beck (eds.), Customary International Humanitarian Law, Vol. I., CICR / Cambridge University Press, Cambridge, 2005, pp. 604 y ss.

87 CICR, El Principio de Jurisdicción Universal. Documento de trabajo, Documento de trabajo del CICR, p. 4.

$88 \quad$ Ibid., loc. cit.

$89 \quad$ UN Doc. S/25704, pp. 41-42.
} 
CANI (internacionalizado), generando la rápida emergencia de una norma consuetudinaria sobre la materia ${ }^{90}$.

$\mathrm{Al}$ respecto, se debe recordar que el Estatuto del TPEY no incorporó ninguna disposición expresa sobre la comisión de crímenes de guerra en un CANI, sino que fue su jurisprudencia la que hizo tal desarrollo. En efecto, en el caso Tadic luego de afirmarse la no existencia de normas incriminatorias en las disposiciones convencionales aplicables a un CANI así como la no aplicación del régimen de infracciones graves a esta clase de conflictos armados; se concluyó que existían una serie de principios consuetudinarios relativos a la conducción de las hostilidades, cuya violación sí genera responsabilidad internacional individual, incluso en un $\mathrm{CANI}^{91}$. A su vez el Estatuto del TPR incluyó un artículo (el cuarto) por el que se atribuyó responsabilidad internacional individual en caso de violaciones al artículo 3 común y al PA II criminalizando por primera vez esas normas, a nivel de DI. Lo anterior fue desarrollado por el case law del TPR.

La segunda dificultad se relaciona con el principio nullum crimen sine lege o principio de legalidad. Respecto a ello, debemos recordar que en el DI el principio de legalidad no puede ser equiparado con la necesaria existencia de una norma convencional. En efecto, no se puede considerar que se viola tal principio, si es que se pretende sancionar una violación seria del DIH y que es contraria al DI en general ${ }^{92}$. De manera similar al Tribunal de Nüremberg, el TPEY superó este obstáculo.

Consideramos, en esa dirección, que la generación de responsabilidad internacional individual por violaciones graves del DIH en un CANI supera las dificultades enunciadas. Prueba de ello es que el Estatuto de la CPI ha penalizado tales conductas desarrolladas en un CANI, cristalizando la respectiva norma consuetudinaria. En tal sentido, el CICR, respecto a tal cristalización ha señalado que "Las personas que cometen crímenes de guerra son penalmente responsables de ellos"93. En cualquier caso, consideramos que aún sin la entrada en vigor del Estatuto de la CPI, se hubiera producido la cristalización de la norma consuetudinaria en cuestión a la luz del desarrollo actual de las fuentes del DI.

\footnotetext{
90 Condorelli, Luigi, « La Cour Pénale Internationale: un pas de géant (Pourvu qu'il soit accompli...) » en Revue Générale de Droit International Public, tomo 103, n. ${ }^{\circ} 1,1999$, p. 12.

91 Prosecutor vs. Tadic, caso n. ${ }^{\circ}$ IT-94-I-AR72, decisión de la Cámara de Apelación relativa a la Moción de la Defensa sobre la Jurisdicción de 2 de octubre de 1995, parágrafo 129.

92 Greenwood, Chistopher, "International Humanitarian Law and the Tadic case" en European Journal of International Law, vol. 7, n. ${ }^{\circ} 2,1996$, p. 281.

93 Henckaerts, Jean-Marie y Louise, Doswald-Beck (eds.), op. cit., pp. 551-555.
} 
Surgimiento y consolidación de la responsabilidad internacional individual por crímenes de guerra cometidos en conflictos armados no internacionales

\section{Reflexión final}

La responsabilidad internacional del individuo por crímenes de guerra en el contexto de un CANI obedece a la formación de una "costumbre de alta velocidad". Tal formación se dio a nivel de DI a través de las resoluciones del Consejo de Seguridad, en especial en los conflictos armados acaecidos en la ex Yugoslavia y Ruanda; los trabajos de la CDI, en particular el Proyecto de Código de Crímenes contra la Paz y Seguridad de la Humanidad de 1996 y en el proceso de negociación del Estatuto de la CPI. A nivel de práctica estatal tenemos que, las declaraciones estatales, la expedición de manuales militares, legislaciones nacionales así como la jurisprudencia de tribunales internos son ejemplo de lo antes enunciado. Finalmente, el Estatuto de la CPI va a cristalizar esta costumbre al reconocer de manera expresa la comisión de crímenes de guerra en un CANI. En la actualidad se reconoce la existencia de la respectiva norma consuetudinaria de DIH. En todo caso, nuevamente la jurisprudencia del TPEY es esclarecedora al señalar que lo que es inhumano y por ende prohibido en un CAI también debe serlo en un CANI ${ }^{94}$.

\section{BIBLIOGRAFÍA}

\section{A/ Obras}

1.- CASSESE, Antonio: International Criminal Law, Oxford University Press, Oxford, 2003.

2.- HENCKAERTS, Jean-Marie y Louise, DOSWALD-BECK (eds.): Customary International Humanitarian Law. Vols. I y II., CICR / Cambridge University Press, Cambridge, 2005.

3.- SASSÒLI, Marco y Antonio, BOUVIER (eds.): How does law protect in war?, CICR, Genève, 1999.

4.- VERRI, Pietro: Diccionario de Derecho Internacional de los conflictos armados, Tercer Mundo Editores, Bogotá, 1998.

\section{B/ Artículos}

1.- CICR. El Principio de Jurisdicción Universal. Documento de trabajo CICR.

2.- CONDORELLI, Luigi: «La Cour Pénale Internationale: un pas de géant (Pourvu qu'il soit accompli...) », en Revue Générale de Droit International Public, tomo 103, n. ${ }^{\circ}$, 1999, pp. 7- 21.

3.- FERNÁNDEZ DE GURMENDI, Silvia: "El Estatuto de Roma de la Corte Penal Internacional: Extensión de los crímenes de guerra a los conflictos armados de carácter no internacional y otros desarrollos relativos al Derecho internacional humanitario", en AAVV, Derecho internacional humanitario y temas de área vinculadas, CICR / Facultad de Derecho de la UBA/ Abeledo-Perrot, Buenos Aires, 2003, pp. 391-413.

Prosecutor vs. Tadic, caso n. ${ }^{\circ}$ IT-94-I-AR72, decisión de la Cámara de Apelación relativa a la Moción de la Defensa sobre la Jurisdicción de 2 de octubre de 1995, parágrafo 119. 
4.- GRADITSKY, Thomas: "La Responsabilidad penal por violación del derecho internacional humanitario aplicable en situación de conflicto armado no internacional", en Revista Internacional de la Cruz Roja, n. ${ }^{\circ}$ 145, 1998, pp. 31-61.

5.- GREENWOOD, Cristopher: "International Humanitarian Law and the Tadic Case", en European Journal of International Law, vol. 7, n. ${ }^{\circ}$ 2, 1996, pp. 265-283.

6.- LEKHA, Chandra: "Revolutions in Accountability: New Approaches to Past Abuses" en American University International Law Review, vol. 19, n. . 2, 2003, pp. 301- 429.

7.- MERON, Theodor: "International Criminalization of Internal Atrocities", en American Journal of International Law, vol. 89, n. ${ }^{\circ}$ 3, 1995, pp. 574-579.

8.- "Is International Law Moving Towards Criminalization?", en European Journal of International Law, vol. 9, n. ${ }^{\circ}$ 1, 1998, pp. 18-32.

9.- "The Humanization of Humanitarian Law", en American Journal of International Law, vol. 94, n. ${ }^{\circ}$ 2, 2000, pp. 239-260.

10.- "General Course on Public International Law", en Recueil des Cours de la Académie de Droit International, volumen 301, 2003, pp. 21-423.

11.- PLATTNER, Dense: “The penal Repression of Violations of International Humanitarian Law Applicable in Non-international Armed Conflicts", en Revista Internacional de la Cruz Roja, vol. 30, 1990, pp. 409-414.

12.- PUEYO LOSA, Jorge: "Hacia un fortalecimiento de los mecanismos de represión de crímenes de guerra. Responsabilidad Internacional del Individuo. Tribunales Internos y Corte Penal Internacional", en PUEYO, Jorge y Julio, URBINA (eds.): El Derecho Internacional Humanitario en una Sociedad Internacional en Transición, Cruz Roja Española / Tórculo Edicións, Santiago de Compostela, 2002, pp. 89-219.

13.- ROBERGE, Marie-Claude: "Los crímenes de guerra en el Estatuto de Roma", en GUEVARA, José y Mariana, VALDÉS (eds.): La Corte Penal Internacional. Ensayos para la Ratificación e Implementación de su Estatuto, Universidad Iberoamericana I Secretaría de Relaciones Exteriores, México D.F., 2002, pp. 67-95.

C/ Sitios web

- COMISIÓN DE DERECHO INTERNACIONAL:

“http://www.un.org/law/ilc" (visitado el día 12 de agosto de 2007)

- COMITÉ INTERNACIONAL DE LA CRUZ ROJA:

"http://www.cicr.org" (visitado el día 12 de agosto de 2007)

- CORTE INTERNACIONAL DE JUSTICIA:

"http://www,icj-cij.org" (visitado el día 12 de agosto de 2007)

- CORTE PENAL INTERNACIONAL:

"http://www.icc-cpi.int/"

(visitado el día 12 de agosto de 2007) 
Surgimiento y consolidación de la responsabilidad internacional individual por crímenes de guerra cometidos en conflictos armados no internacionales

- $\quad$ TRIBUNAL PENAL INTERNACIONAL PARA LA EX YUGOSLAVIA: "http://www.un.org/icty/" (visitado el día 12 de agosto de 2007)

- $\quad$ TRIBUNAL PENAL INTERNACIONAL PARA RUANDA: "http://www.ictr.org."

(visitado el día 12 de agosto de 2007) 